\title{
The Impact Of Consumer Attitudes About Bioengineering On Purchase Behavior Intentions: Moderating Effects Of Innate Consumer Innovativeness And Anxiety
}

Sarath A. Nonis (E-mail: snonis@astate.edu), Arkansas State University Gauri S. Guha (E-mail: gguha@astate.edu), Arkansas State University Richard Segall (Email: rsegall@astate.edu), Arkansas State University

\section{Introduction}

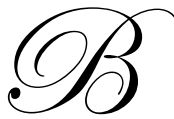

iotechnology is anticipated to be the next generation of innovations and is predicted to surpass the IT revolution in terms of economic prosperity (Darby and Zucher, 2003). But available behavioral and social research relating to biotechnology is at its infant stage. Most studies are qualitative in nature (i.e., focus groups) and are limited to public policy issues such as awareness, knowledge, and perception of risks (Bredahl, 1999; Frewer et al., 1997; Frewer, Howard, and Shepherd, 1997). According to Bredahl, 2001, few research projects have yet to determine how consumer attitudes can be expected to influence subsequent purchase behavior intentions with genetically modified products. As the U.S. Food and Drug Administration (FDA) continues to approve more and more inventions of biotechnology (i.e., foods such as genetically engineered potatoes and rice; industrial plastic from genetically modified organisms; and life saving pharmaceuticals for diseases such as cancer, HIV, and Alzheimer's) there is a need for research that investigates how consumer attitudes about genetically modified products influence their purchase intentions and subsequent purchase behavior. The primary purpose of this research is to investigate how consumer attitudes about bioengineering influence their purchase behavior intentions. Second, the influence of two personal variables innate consumer innovativeness and general anxiety about bioengineering as they relate to purchase behavior intentions will be investigated. Finally, the study also makes an attempt to determine if the relationship between attitude and behavior intentions is moderated by the two personal variables innate consumer innovativeness and general anxiety about bioengineering. Personal variables such as these can reasonably be expected to have a differential impact on the relationship between attitude about bioengineering and purchase behavior intentions. That is, the strength of the relationship between attitude and purchase behavior intentions is likely to be stronger for consumers that are innovative and less anxious about bioengineering than others.

The study results have implications for both researchers and promoters of bioengineering. For researchers, it should be noted that an extensive literature search was unable to find any empirical research to date that have investigated the moderating effects on the relationship between attitude about bioengineering and purchase behavior intentions. For practitioners, the study will aid biotechnology firms in their efforts in building a more positive attitude about biotechnology in general and to identify the profile of consumers that are more likely to purchase and use products of this technology. 


\section{Theoretical Background and Hypotheses To Be Tested}

\section{Relationship Between Attitudes and Purchase Behavior Intentions}

Because attitudes are recognized as one major factor that guides human behavior, it is reasonable to expect a relationship between attitudes about bioengineering and likely purchase behavior. However, according to Fazio and Zann (1978; 1981), attitudes towards emergent attitude objects (i.e., bioengineering) are often weak at best and therefore can be poor predictors of behavior. This is because these attitudes maybe based on indirect experiences consumers have with the attitude object. Bioengineering, even though it has been going on for decades is a relatively a new phenomenon brought to consumer attention mainly by the media and special interest groups such as Greenpeace. In addition, close to $80 \%$ of soy and $30 \%$ of corn in the U.S food supply is genetically engineered (Elias, 2003) but few consumers are aware of it because these products are yet marketed and labeled as such. As a result, consumers have very limited, if any, direct product experience of which they are aware. Also, their attitudes about purchasing products such as food, medicine, and industrial products that are genetically engineered is likely to be influenced by their general attitude not product specific attitude about bioengineering.

Bioengineering, the precise manipulation of crops and animals has been shown to be a process of great social and individual involvement that is likely to significantly transform our future life. Attitudes that reflect such high involvement are mostly based on higher order values such as attitude towards nature and technology (Frewer et al., 1997; Sparks, Shepherd, and Frewer 1994; Thomsen, Borgida, and Lavine 1995). Based on available theoretical (Juanillo, 2001) and empirical research (Frewer et al., 1997), six plausible general attitude dimensions of bioengineering can be conceptualized. They are, (1) trust and credibility of regulatory agencies, (2) perceived risks for health and environment, (3) fear of the unknown, (4) ethics and morality, (5) increased power for biotech firms, and (6) perceived benefits of biotechnology. In this study, these six attitude dimensions are defined as follows:

- $\quad$ Trust and credibility of regulatory agencies. Perception of government regulatory agencies such as the FDA and USDA as trusted sources of information on product related benefits and risks.

- $\quad$ Perceived risk for health and environment. Perception of potential health risks to consumer as well as negative consequences for the natural ecosystem.

- $\quad$ Fear of the unknown. Perceived fear of genetic engineering causing unknown and incalculable harm to self and the environment (i.e., Franken-foods).

- $\quad$ Ethics and morality. Belief that nature is pure, and all that is natural is valuable and good in itself and biotechnology tampers with nature.

- $\quad$ Increased power for biotechnology firms. Perception that bioengineering will give too much power to firms dealing with biotechnology because of new innovations and patents. The power of farmers and consumers will be marginalized.

- $\quad$ Perceived benefits. Perception that genetic engineering will provide benefits to the environment (seeds that require less pesticide) and self (i.e, therapeutic medicines as well as nutritional foods).

These six attitude dimensions of bioengineering form an important theoretical basis for the primary purpose of this research. While some empirical research have attempted to investigate the relationship between two of the above mentioned attitude dimensions perceived risks and perceived benefits and consumer behavior intentions toward genetically modified products (cf. Bredahl, 2001), no studies could be identified that have evaluated the relationships between the remaining four attitude dimensions and consumer behavior intentions of genetically modified products. Therefore, this study attempts to determine if the six proposed attitude dimensions of bioengineering influence consumer purchase behavior intentions. This leads to the first hypothesis:

H1: Attitude dimensions trust and credibility of regulatory agencies, perceived risks for health and environment, fear of the unknown, ethics and morality, increased power for biotech firms, and perceived benefits of biotechnology influence the consumer behavior intentions of genetically modified products. 


\section{Relationship Between Individual Difference and Purchase Behavior Intentions}

Consumer researchers interested in the diffusion of innovation wish to measure innovativeness so that they can either assign consumers to a single adopter category (e.g., innovator, early adopter, early majority, late majority, or laggard) or examine the relationships between their measure of innovativeness and other variables. Marketing managers need to identify the potential consumers in a target segment to adopt a new product.

In this study consumer innovativeness is measured as innate consumer innovativeness that is defined as an individual's inherent personality, predisposition, and cognitive style toward innovations that can be applied to consumption domains across product classes. Obviously, individuals that are innately innovative are more likely to purchase products that are genetically modified than other. Studies have emphasized the relationship between new product adoption behavior and innate consumer innovativeness as a generalized predisposition in industries such as fashion, and software products (Foxall, 1988; Goldsmith, Freiden, and Eastman, 1995; Manning, Bearden, and Madden, 1995; Midgley and Dowling, 1978). This leads to the second hypothesis:

H2: A consumer's innate innovativeness will influence his or her behavior intentions toward genetically modified products.

Research examining responses of fear or anxiety to messages about bioengineering is scarce and warrants greater attention. Public anxiety of potential environment and health risks often exceed what neutral experts contend the actual danger is (Ropeik, 2002). There is usually a gap between fear and fact and special interest groups such as Greenpeace as well as journalists rarely explain why such a gap exists. Of course, the fears are usually prominently featured in coverage and consumers receive most of their information about innovative products that are genetically engineered through such communication sources. Therefore, investigation of fear or anxiety that is directed towards bioengineering and how this anxiety may influence behavior intentions has implications for both opponents and proponents of bioengineering in terms of their communications strategy. Anxiety here is defined as a, "chronic emotional state directed at the potential negative consequences of bioengineering." High anxiety has been found to discourage individuals from paying attention to a persuasive appeal, and from acting upon it (Sutton, 1982). This leads to the next hypothesis:

H3: Anxiety associated with genetic engineering will negatively influence the consumer behavior intentions of genetically modified products.

\section{Moderating Effects of Individual Difference Variables}

Some research has explored the role of personal characteristics such as age and income in moderating the relationship between innate consumer innovativeness and new-product adoption behavior. As suggested by Midgley, Dowling, Grahame (1978), consumers with high innovative dispositions may not always adopt new products earlier than others due to moderating factors (e.g., Steenkamp, Hofstede, and Wade, 1999). In this study, innate consumer innovativeness is hypothesized as the moderator that influences the relationship between attitude and behavior intentions. This is because the relationship between attitude and behavior intentions is well established (Fishbein and Ajzen, 1975). This leads to the next hypothesis:

H4: Innate consumer innovativeness will moderate the relationship between attitude dimensions trust and credibility of regulatory agencies, perceived risks for health and environment, fear of the unknown, ethics and morality, increased power for biotech firms, and perceived benefits of biotechnology and the consumer behavior intentions of genetically modified products.

It is intuitively plausible to expect a relationship between attitude about bioengineering and behavior intentions to vary as a function of anxiety a person associates with bioengineering. To the extent that an individual has less anxiety, it seems as though the influence of attitudes about bioengineering will have a stronger impact on behavior intentions of genetically modified products. This intuitively plausible yet theoretically unposited line of reasoning underlies the final hypothesis: 
H5: Anxiety about genetic engineering will moderate the relationship between attitude dimensions trust and credibility of regulatory agencies, perceived risks for health and environment, fear of the unknown, ethics and morality, increased power for biotech firms, and perceived benefits of biotechnology and consumer behavior intentions of genetically modified products.

Figure 1 summarizes the network of constructs and relationships between constructs proposed and evaluated here. The genetically modified product that is investigated here is limited to a food product.

\section{Figure 1}

\section{Conceptual Framework}

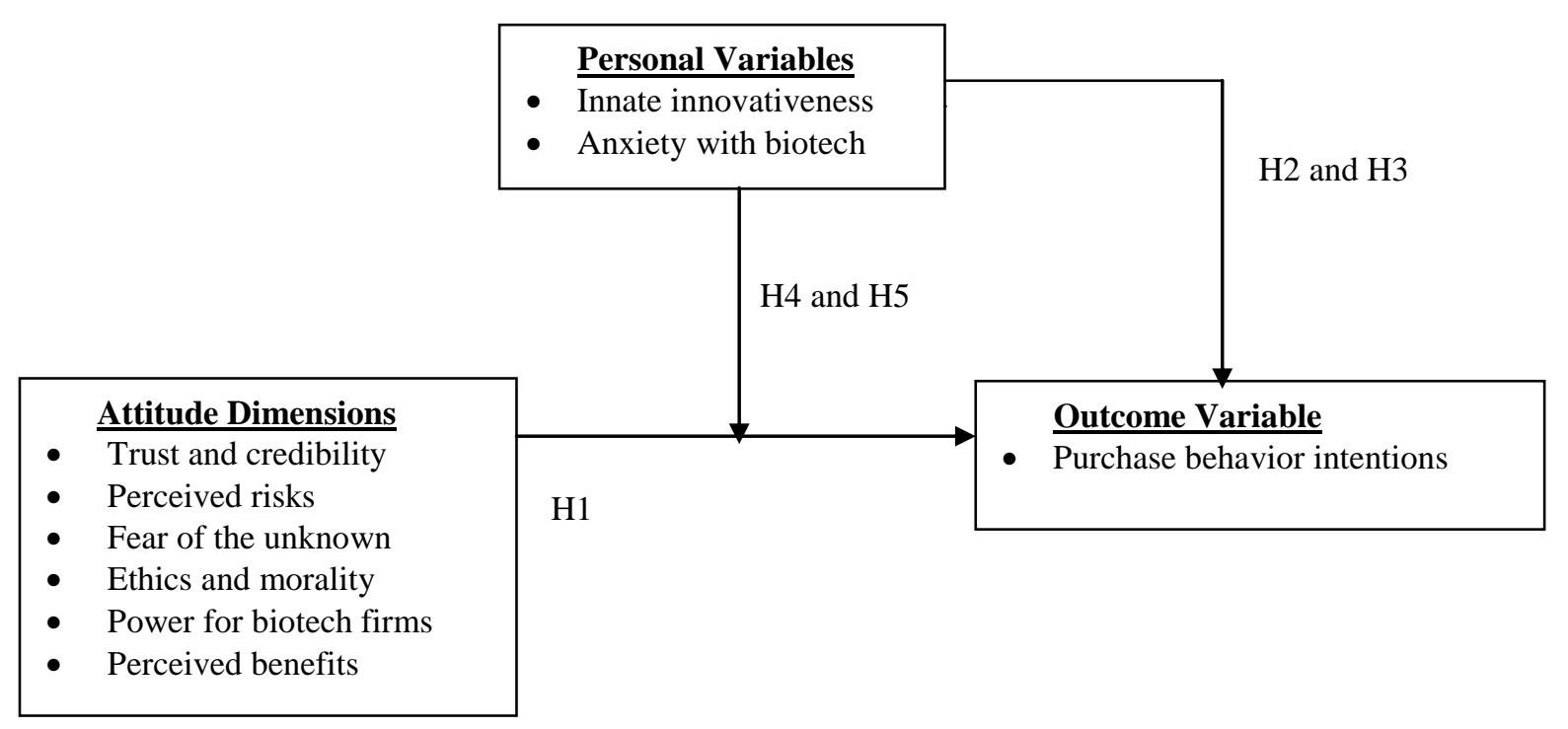

Method

Sample

The hypotheses were tested using a convenience sample of 133 students attending a medium-size $(10,000+$ students) AACSB accredited state university in the South. Surveys were administered in junior, senior, and graduate level business courses and participation was completely voluntary. The survey took 10 to 15 minutes to complete and respondents were assured of confidentiality and anonymity. Because awareness and knowledge precede attitude formation, it was decided to use students as opposed to the general public as the sample. College students are more likely be aware and somewhat knowledgeable about bioengineering than the general public. For example, only 53\% of American consumers are aware of biotechnology at the moment (Hoban, 2001).

Results show sample characteristics to be as follows: gender (50\% males and 50\% females), marital status (76.6\% single, $15.3 \%$ married without children, and $8.1 \%$ married with children), student classification (62.9\% undergraduate and $37.1 \%$ graduates), and age (24.95 years).

\section{Measurement}

Innate consumer innovativeness. This construct was operationalized using the Kirton Adaption-Innovation Inventory (KAI) (Kirton, 1976). This particular inventory of items have been extensively tested for reliability, 
content validity, generalizability, and factor structure in numerous contexts (Bagozzi and Foxall,1996; Foxall and Hackett, 1992).

Anxiety associated with bioengineering. The scale developed Sego and Stoutt (1994), was used to measure individual anxiety associated with bioengineering. The measure taps four underlying dimensions of the construct: (1) "uncomfortable," factor assessing general societal concern, discomfort, and irritation with the issue, (2) "tense," factor representing symptoms such as loss of appetite associated with the issue, (3) "rational," factor assessing a cognitive dimension of a lack of an ability to think rationally about the issue, and (4) "decisive" factor which assesses discouraging individuals from conversing about the issue, attending media reports about the issue, and intending to support the issue. A total of 15 items tap the construct and all items are scored on a 5-point Likert scale ranging from 1 "strongly disagree" to 5 "strongly agree."

Attitudes about bioengineering. Based on published articles in academic and practitioner journals, magazines, newspapers, and TV programs, 74 statements were developed to measure the six general attitudes of bioengineering. The response for each item ranged from 1 "strongly disagree" to 5 "strongly agree." Three experts evaluated each item for content validity prior to including the item in the survey. Results from reliability analysis is provided in the next section. Sample items are provided in Appendix A.

Likely consumer behavior intentions of bioengineering. Individuals were asked to respond to the survey item, "if there is a food product currently in the market that is approved as safe by FDA but is genetically engineered, how likely are you to purchase it for consumption?" A behavioral intention reflects a person's decision to perform a behavior, and the concept is based on the idea that a decision to engage in a certain behavior will be realized only to the extent that the person is in full control of performing the behavior (Fishbein and Ajzen 1975). Comparable items have been used as a surrogate for behavior in other similar studies (Bredahl, 1999).

Data Analysis

Partial correlation coefficients were computed to test hypotheses $\mathrm{H} 1, \mathrm{H} 2$, and $\mathrm{H} 2$. When evaluating the bivariate relationship between each attitude dimension and behavior intention variable in hypothesis $\mathrm{H} 1$, the influence of other attitude dimensions were controlled so that the analysis would detect only a true relationship (and not a relationship due to other extraneous variables). When evaluating the relationship between innate consumer innovativeness and likely behavior intentions, the influence of anxiety about bioengineering as well as demographic variables gender, age, and marital status were controlled. Demographic variables and innate consumer innovativeness was controlled for when investigating the relationship between anxiety with bioengineering and purchase intentions.

As suggested by Sharma, Durand, and Gur-Arie (1981), the moderating effect of innate consumer innovativeness on the slope of the attitude-behavior intention relationship was examined by conducting multiple regression analyses of the dependent and independent variables for different subgroups of the sample formed on the basis of innate consumer innovativeness (hypothesis H4). To create high and low subgroups of innate innovativeness, the median value of this variable was used. Then, multiple regression analyses were performed in both subgroups using purchase intentions as the dependent variable and the attitude variables as the independent variables. A similar procedure was used to test hypothesis H5. Two groups of high and low anxiety were formed on the basis of the median score of the variable. This was followed by multiple regression analyses that used purchase intentions as the dependent variable and the attitude variables as the independent variables. This procedure has been used in several key studies and is appropriate if there is justification for the independent variables to influence the dependent variable in a step function (Baron and Kenny 1986; Futrell and Parasuraman 1984). All hypotheses were tested using the traditional 0.05 level of significance.

Table 1 summarizes descriptive statistics, pairwise correlations, and alpha reliabilities for the sample. Except for "decisive" dimension of anxiety, all other measures exhibited acceptable reliabilities as per Nunnally (1978). 
As summarized is Table 2, hypothesis 1 was partially supported. Of the six attitude dimensions only "trust and credibility of regulatory agencies" dimension significantly correlated with behavior intentions $(r=0.30, p<$ 0.05). Partial correlation coefficients between all attitude dimensions and purchase behavior intentions are provided in Table 2.

Table 2

Partial Correlation Coefficients Between Knowledge and Attitude of Bioengineering and Purchase Intentions

\begin{tabular}{lll}
\hline Variable & Partial Correlation & p-value
\end{tabular}

Trust and credibility of regulatory agencies

$\begin{array}{ll}0.30^{1} & 0.00 \\ -0.08 & 0.39 \\ -0.10 & 0.30 \\ 0.08 & 0.41 \\ -0.13 & 0.17 \\ -0.09 & 0.34\end{array}$

Perceived risks

0.00

Fear of the unknown

0.30

Ethics and morality

Increased power for biotech firms

0.17

Perceived benefits of biotech

$-0.09$

0.34

${ }^{1} \mathrm{p}<0.05$

${ }^{\mathrm{a}}$ when investigating each partial correlation between attitude variable and purchase intention, remaining attitude variables were controlled

Hypothesis $\mathrm{H} 2$ was not supported. Partial correlation between innate consumer innovativeness and purchase intentions was not significant $(\mathrm{r}=0.03, \mathrm{p}>0.05)$. Hypothesis 3 was also partially supported. The relationship between "tense" dimension of anxiety and behavior intention was supported $(r=-0.29, \mathrm{p}<0.05)$. However, neither the relationship between "uncomfortable" dimension of anxiety and behavior intention $(\mathrm{r}=-0.13$, $\mathrm{p}>0.05$ ) nor the relationship between "lack of ability to think rationally" dimension of anxiety and behavior intention $(r=-0.10, p>0.05)$ were supported.

As shown in Table 3, hypothesis 4 that tested the moderator influence of innate consumer innovativeness on the relationship between attitudes about bioengineering and behavior intentions was supported. The results of multiple regression analyses for the total sample as well as for the two subgroups of innate consumer innovativeness are summarized in Table 3. For the total sample, the six attitude dimensions together accounted for $13 \%$ of the variance in behavior intentions. However, there is a sharp difference between the high and low innate consumer innovativeness groups in terms of $\mathrm{r}^{2}$ values. While the attitude measures only accounted for $14 \%$ of the behavior intention variable in the low innate consumer innovativeness group, they accounted for $28 \%$ of the behavior intention variable in the high consumer innovativeness group. Table 3 also sheds light on the relative importance of the various attitude dimensions in affecting behavior intentions in the high and low innate consumer innovativeness groups. While no attitude variables were significant in predicting behavior intentions for low consumer innovativeness group, "trust and credibility of regulatory agencies" dimension was significant in predicting behavior intentions for high consumer innovativeness group.

Hypothesis 5 that tested the moderator influence of anxiety about bioengineering on the relationship between attitudes about bioengineering and behavior intentions was also supported. As shown in Table 4, there is a sharp difference between the high and low "uncomfortable" dimensions of anxiety groups in terms of $\mathrm{r}^{2}$ values. While the attitude measures only accounted for $12 \%$ of the behavior intention variable in the high group, they accounted for $26 \%$ of the behavior intention variable in the low group. Evaluation of Table 4 once again shows "trust and credibility of regulatory agencies" dimension was significant in predicting behavior intentions for the low anxiety group. However, "perceived benefits" dimension was also significant in predicting behavior intentions for the low anxiety group but in the direct opposite to what was expected. This finding warrants some explanation that will be provided later in the discussion section. 
Table 3

Results of Multiple Regression Analysis Using Innate Consumer Innovativeness as the Moderator

\begin{tabular}{llll}
\hline Independent Variables & Slope & t-value & $\mathbf{r}^{2}$ \\
\hline
\end{tabular}

\section{Total Sample}

Trust and credibility of regulatory agencies

$\begin{array}{rr}0.38 & 3.41^{1} \\ -0.20 & -1.19 \\ -0.10 & -1.00 \\ 0.09 & 0.72 \\ -0.24 & 1.53 \\ -0.24 & -1.37\end{array}$

0.13

Perceived risks

Fear of the unknown

$-1.00$

Ethics and morality

1.53

Perceived benefits

$-1.37$

\section{High group}

Trust and credibility of regulatory agencies

0.51

$-0.20$

$3.56^{1}$

$-0.78$

Fear of the unknown

$-0.14$

$-1.01$

Ethics and morality

0.29

1.68

Increased power of biotech companies

$-0.17$

0.89

Perceived benefits

$-0.17$

0.62

Low group

Trust and credibility of regulatory agencies

0.15

0.88

$-0.06$

$-0.03$

Perceived risks

$-0.10$

$-0.72$

Fear of the unknown

0.12

0.70

Increased power of biotech companies

$-0.23$

$-0.91$

Perceived benefits

$-0.38$

$-1.65$

${ }^{1} \mathrm{p}<0.05$

As shown in Table 4, there is also a difference between the high and low "tense" dimensions of anxiety groups in terms of $\mathrm{r}^{2}$ values. While the attitude measures only accounted for $14 \%$ of the behavior intention variable in the high group, they accounted for $29 \%$ of the behavior intention variable in the low group. Evaluation of Table 4 once again shows "trust and credibility of regulatory agencies" dimension was significant in predicting behavior intentions for the low anxiety group.

Finally, a significant difference was once again identified between the high and low "lack of ability to think rationally" dimensions of anxiety groups in terms of $\mathrm{r}^{2}$ values. While the attitude measures only accounted for $13 \%$ of the behavior intention variable in the high group, they accounted for $27 \%$ of the behavior intention variable in the low group. Evaluation of Table 4 shows "trust and credibility of regulatory agencies" dimension to be once again significant in predicting behavior intentions for the low anxiety group. However, "perceived benefits" dimension was also significant in predicting behavior intentions for low anxiety group but in the direction opposite to what was expected. Plausible explanation will be provided in the next section. 
Table 4

Results of Multiple Regression Analysis Using Anxiety with Bioengineering as the Moderator

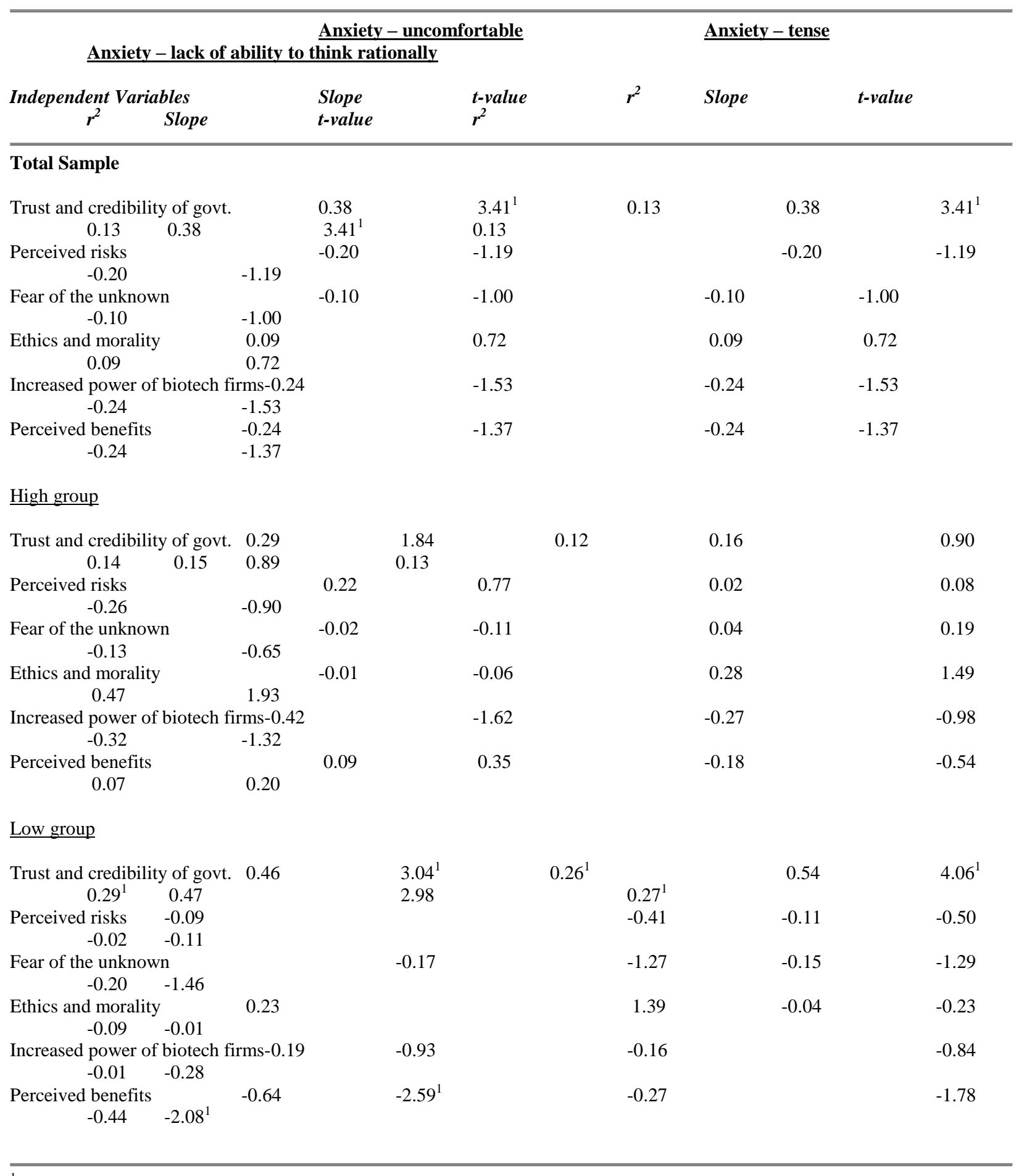

${ }^{1} \mathrm{p}<0.05$ 


\section{Discussion}

Results of this study shows consumer attitudes about bioengineering influences their purchase behavior intentions (hypothesis H1). However, this relationship was only significant for the attitude dimension "trust and credibility of regulatory agencies." The positive relationship shows consumer intentions to purchase bioengineered products increase when he/she believes regulatory agencies are credible and can be trusted to deal with safety issues to the health and the environment. However, the remaining five attitude dimensions did not show any significant relationship with purchase intentions. Since the public is only recently becoming aware of the pros and cons of bioengineering, attitudes related to these issues are weak and therefore can be poor predictors of behavior intentions (Fazio and Zanna, 1981).

The individual difference variable innate consumer innovativeness did not demonstrate any significant relationship with purchase behavior intentions (hypothesis H2). While this was unexpected, in his study of new product adoption behavior, Foxall (1995) found innate consumer innovativeness to positively relate with behavior intentions in the software product category but not in the food product category. Also, Manning, Bearden, and Maddan (1995) found innovativeness as novelty seeking related to initial adoption stage, while innovativeness as communication independence (determined by the degree to which a consumer's decision process is independent of others' personal influence in the social system) is more related to the later stages of new product trail. Clearly, genetically engineered food not being a novelty product that is not communication independent may explain the lack of a significant relationship.

All three dimensions of the individual difference variable anxiety about bioengineering showed inverse relationships with purchase intentions as expected, but only the "tense" dimension showed a statistically significant relationship (hypothesis H3). Tense dimension includes symptoms such as nervousness or anxiety not being able to get the issue about bioengineering off one's mind. This dimension represents the most serious symptoms compared to the remaining two dimensions of anxiety.

Results also found innate consumer innovativeness to moderate the relationship between the attitude dimensions "trust and credibility of regulatory agencies" and purchase behavior intentions. As shown in Table 3, the relationship between the attitude "trust and credibility of regulatory agencies" and purchase behavior intentions was significant and stronger for individuals with high levels of innate consumer innovativeness than others. Clearly, trust and credibility of regulatory agencies had no influence on purchase behavior intentions for the individuals with low levels of consumer innovativeness and this have implications for biotechnology firms in their communication efforts.

Similar results were found for the moderator effects of anxiety about bioengineering. As shown in Table 4, anxiety about bioengineering moderated the relationship between the attitude and purchase intentions. The relationship between the attitude dimension "trust and credibility of regulatory agencies" and purchase behavior intentions was moderated by all three dimensions of anxiety about bioengineering. The relationship between the attitude "trust and credibility of regulatory agencies" and purchase behavior intentions was significant and stronger for individuals with low levels of anxiety than others. Trust and credibility associated with regulatory agencies had no influence on purchase behavior intentions for the individuals that demonstrated high levels of anxiety. The relationship between the attitude dimension "perceived benefits" and purchase intentions was also moderated by two of the anxiety dimensions "uncomfortable" and "lack of ability to think rationally," but in the direction opposite to what was expected. The negative and significant slope coefficient for low anxiety groups suggests consumers in this group to be more likely to purchase bioengineered products even if they do not perceive important benefits of this technology. Once again this finding has implications for biotechnology firms.

\section{Implications and Direction for Future Research}

Biotechnology firms should put great emphasis on consumer attitude dimension trust and credibility of regulatory agencies such as the FDA or USDA. For example, all bioengineered products that are in the market at 
the moment are approved by FDA and USDA under very stringent and formal guidelines. This has to be emphasized and communicated to the consumer in all public announcement campaigns.

Second, not identifying any negative relationship between attitude variables "perceived risks of biotechnology to the health and environment" as well as "ethics and morality" and purchase intentions should be encouraging to biotechnology firms. Clearly, these attitudes do not seem to have any significant impact on consumer intentions to purchase. But, the sample is small and constituted only college students, and therefore results cannot be generalized to the larger public. Future studies involving a larger sample that is more representative of the population should confirm if this finding is only confined to college students or whether they can be generalized to larger populations.

Third, biotechnology companies should make an attempt to identify the profile of likely consumers of bioengineered products. This study has identified two such individual variables - innate consumer innovativeness and anxiety about bioengineering. These individuals are more likely to purchase products at the early stage of the product diffusion process. Studies can be conducted to identify the characteristics of these individuals. In general, income, age, level of education and social status are four variables that characterize innovators (Gatignon and Robertson 1991; Rogers, 1995; Uhl, Andrus, and Poulsen, 1970). However, studies should be undertaken to determine if such generalizations can be made with regards to inventions of biotechnology.

Fourth, the dependent variable in this study was limited to purchase intentions of a food product. There are several genetically modified medicines and industrial products that are available in the market. Studies can be undertaken to see if similar relationships can be identified in different product categories.

\section{References}

1. Bagozzi, Richard P., and Foxall, Gordan R. (1988). "Construct validation of a Measure of AdaptiveInnovative Cognitive Style in Consumption," International Journal of Research in Marketing, 13, 201-213.

2. Barron, R.M., and Kenny, D.A. (1986). "The Moderator-mediator Variable Distinction in Social Psychology Research: Conceptual, Strategic, and Statistical Considerations," Journal of Personality and Social Psychology, 51 96): 1173-1182.

3. Bredahl, Lone (2001). "Determinants of Consumer Attitudes and Purchase Intentions With Regards to Genetically Modified Foods - Results of a Cross-National Survey," Journal of Consumer Policy, 24 (1): 23-61.

4. Bredahl, Lone (1999). "Consumer Cognitions With Regard to Genetically Modified Foods-Results of a Qualitative Study in Four Countries," Appetite, 34, 343-360.

5. Chow, G.C. (1960). "Test of Equality Between Sets of Coefficients in Two Linear Regression," Econometrika, 28 (July): 591-605.

6. Darby, Michael, and Zucher, Lynne G. (2003). "Growing by Leaps and Inches: Creative Destruction Real Cost Reduction and Inching Up," Economic Inquiry, Forthcoming.

7. Elias, Paul (2003). "Biotech Inventors Look at New Ways to modify Crops," The Jonesboro Sun, June 29 (Sunday): 13B.

8. Fazio, R.H., and Zanna, M.P. (1981). "Direct Experience and Attitude-Behavior Consistency," In: L. Berkowitz (Ed.), Advances in Experimental Social Psychology, 14, 161-202, New York: Academic Press.

9. Fazio, R.H, and Zanna, M.P. (1978). "On the Predictive Validity of Attitudes: The Roles of Direct Experience and confidence," Journal of Personality, 46, 228-243.

10. Fishbein, M., and Ajzen I. (1975). Belief, Attitude, Intentions, and Behavior: An Introduction to Theory and Research. Reading, MA: Addison-Wesley.

11. Frewer, L.J., Hedderley, D., Howard, C., and Shepherd, R. (1997). "Objection Mapping in Determining Group and Individual Concerns Regarding Genetic Engineering," Agriculture and Human Values, 14, 6769.

12. Frewer, L.J., Howard, C., and Shepherd, R. (1997). "Public Concerns in the United Kingdom About General and Specific Applications of Genetic Engineering: Risk, Benefit, and Ethics," Science, Technology, and Human Values, 22, 98-124. 
13. Foxall, Gordan R. (1995). "Cognitive Styles of Consumer Initiators.” Technovation, 15 (5): 269-288.

14. Foxall, Gordan R. (1988). "Consumer Innovativeness: Novelty Seeking, Creativity, and Cognitive Style," Research in Consumer Behavior, 3, 79-113.

15. Foxall, Gordan R., and Hackett, Paul M.W. (1992). "The Factor Structure and Construct Validity of the Kirton Adaption-Innovation Inventory," Personality and Individual Differences, 13 (19): 967-975.

16. Futrell, Charles M., and Parasuraman, A. (1984). "The Relationship of Satisfaction and Performance to Salesforce Turnover," Journal of Marketing, 48 (Fall): 33-40.

17. Gatignon, Hubert, and Robertson, Thomas S. (1991). "Innovative Decision Process," In Handbook of Consumer Behavior, Eds. Thomas S. Robertson and Harold H. Kassarjian. Englewood Cliffs, NJ: Prentice Hall.

18. Goldsmith, Ronald E., Freiden, Jon B., Eastman, Jacqueline K. (1995). "The Generality/Specificity Issue in Consumer Innovativeness Research," Technovation, 15 (19): 601-611.

19. Hoban, Thomas J. (2001). "American Consumers' Awareness and Acceptance of Biotechnology," NABC Council Meeting, Winter/Spring: 1-11.

20. Juanillo, Napoleon (2001). "The Risks and Benefits of Agricultural Biotechnology," American Behavioral Scientist, 44 (8): 1246-1266.

21. Kirton, Michael (1976). "Adaptors and Innovators: A Description and Measure," Journal of Applied Psychology, 61 (5): 622-629.

22. Manning, Kenneth C., Bearden, William O., and Madden, Thomas, J. (1995). "Consumer Innovativeness and Adoption Process," Journal of Consumer Psychology, 4 (4): 329-345.

23. Midgley, F. David, and Dowling, Grahame, R. (1978). "Innovativeness: The Concept and Its Measurement," Journal of Consumer Research, 4 (March): 229-242.

24. Nunnally, Jum C. (1978). Psychometric Theory. New York: McGraw-Hill Book Company.

25. Roberts, Everett M. (1995). Diffusion of Innovations, New York: Free Press.

26. Ropeik, David (2002). "Journalists Can Be Seduced by Aspects of Risks," Nieman Reports, Vol. 56 (4): 51-52.

27. Sego, Trina, and Stoutt, Patricia (1994). "Anxiety Associated With Social Issues: The Development of a Scale to Measure an Antecedent Construct," in Chris Allen and Deborah Roedder John (Eds.), Advances in Consumer Research, 21, 601-606. Provo, UT: Association for Consumer Research.

28. Sharma, Subash, Durand, Richard M., and Gur-Arie, Oged (1981). "Identification and Analysis of Moderator Variables," Journal of Marketing Research, 18 (August): 291-300.

29. Sparks, P., Shepherd, R., and Frewer, L.J. (1994). "Gene Technology, Food Production, and Public Opinion: A United Kingdom Study," Agriculture and Human Values, 11, 19-28.

30. Steenkamp, Jan-Benedict E., Hofstede, Frenkel ter, and Wadel, Michael (1999). "A Cross-National Investigation Into the Individual and National Cultural Antecedents of Consumer Innovativeness," Journal of Marketing, 63 (April): 55-69.

31. Thomsen, C., Borgida, E., and Lavine, H. (1995). "The Causes and Consequences of Personal Involvement," In: R.E. Petty and J.A. Krosnick (Eds.), Attitude Strength-Antecedents and Consequences, 191-214, Mahwah, NJ: Lawrence Erlbaum.

32. Uhl, K., Andrus, R., and Poulsen, L. (1970). "How Are Laggards Different? An Empirical Inquiry," Journal of Marketing Research, 7, 51-54. 


\section{Appendix A \\ Constructs and Measures}

\begin{tabular}{|c|c|c|}
\hline Construct & $\begin{array}{l}\text { Number of } \\
\text { Items }\end{array}$ & Sample Items \\
\hline Perceived risks $^{2}$ & 3 & $\begin{array}{l}\text { Genetically engineered food is not safe for human consumption } \\
\text { All genetically engineered products (food, medicines) have negative consequences to } \\
\text { consumer health }\end{array}$ \\
\hline $\begin{array}{l}\text { Increased power for } \\
\text { biotech firms }\end{array}$ & 3 & $\begin{array}{l}\text { Genetically engineered crops and animals benefit only large corporations. There is zero } \\
\text { benefit for the consumer } \\
\text { Genetically engineered foods increase company profits at the risk of endangering public } \\
\text { health }{ }^{\text {a }}\end{array}$ \\
\hline Ethics and morality ${ }^{2}$ & 3 & $\begin{array}{l}\text { Genetic manipulation of food crops and animals are not morally acceptable } \\
\text { Under any circumstances, genetic engineering is wrong }\end{array}$ \\
\hline Benefits of biotech ${ }^{2}$ & 3 & $\begin{array}{l}\text { Benefits of genetic engineering of crops and animals are far-fetched and superfluous }{ }^{\text {a }} \\
\text { Genetic engineering has helped farmers grow better, more nutritious and hardier crops } \\
\text { with fewer inputs }\end{array}$ \\
\hline Trust and credibility of & 3 & $\begin{array}{l}\text { There is not enough oversight by governmental agencies of companies that are involved } \\
\text { in genetic engineering a }\end{array}$ \\
\hline Government agencies $^{2}$ & & $\begin{array}{l}\text { Governmental regulatory agencies such as FDA and USDA can always be trusted to keep } \\
\text { away food and other products that are unsafe for consumption and/or use }\end{array}$ \\
\hline Fear of the unknown ${ }^{2}$ & 2 & $\begin{array}{l}\text { No one knows for sure the long-term consequences for human health of genetically } \\
\text { engineered crops } \\
\text { No one knows for sure the long-term consequences for the wider environment of } \\
\text { genetically engineered crops }\end{array}$ \\
\hline
\end{tabular}

\footnotetext{
${ }^{1}$ Possible responses were $1=$ True, $2=$ False, $3=$ Don't Know

${ }^{2}$ Possible responses were 1 = Strongly disagree, $2=$ Disagree, $3=$ neither disagree nor agree, $4=$ agree, $5=$ strongly agree

${ }^{\text {a }}$ Reverse coded items
} 
